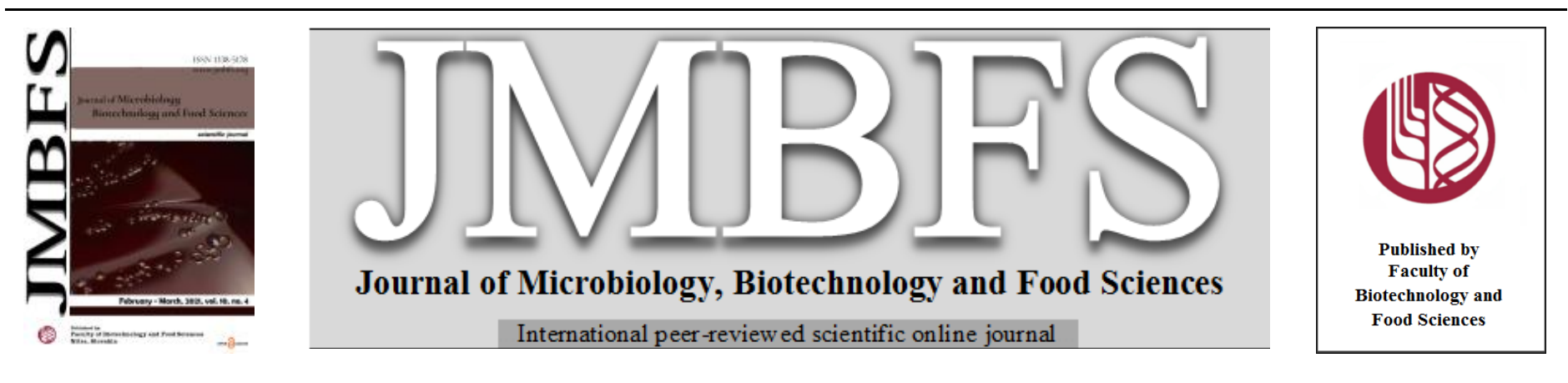

\title{
METHODS FOR THE CULTURE CONSERVATION OF EDIBLE AND MEDICINAL FUNGI
}

\author{
Laura P. Bermeo Escobar ${ }^{I}$, Katherin Castro-Rios ${ }^{2 *}$ \\ $\operatorname{Address}(e s)$ : \\ ${ }^{1}$ SENNOVA CFC, Servicio Nacional de Aprendizaje, Km 10 vía al Magdalena, Manizales, Colombia. \\ ${ }^{2}$ Instituto de Investigación en Microbiología y Biotecnología Agroindustrial, Universidad Católica de Manizales, Cra 23 No. 60, Manizales, Colombia.
}

*Corresponding author: katherin.castro@protonmail.ch

doi: 10.15414/jmbfs.2021.10.4.620-625

ARTICLE INFO

Received 27. 12. 2019

Revised 25. 9. 2020

Accepted 27. 10. 2020

Published 1. 2. 2021

Regular article

open $\mathcal{O}$ access

\begin{abstract}
The maintenance and conservation of strains of microorganisms such as bacteria, yeast, and fungi are vital for the advancement and development of various life science areas, impacting studies in genetics, biodiversity, bioprospecting, biotechnology, medicine, veterinary, environment, food security, nutrition, among others. The preservation of this biological material has achieved the safeguarding of industrial potential and the possibility of researching new functions and the use for the benefit of humanity. Various culture preservation methods have been developed over the years, such as sterile distilled water, cryopreservation, freeze-drying, subculture, and sterile mineral oil; these allow storing strains of various microorganisms under appropriate conditions and for long periods. For the case of edible and medicinal fungi, the most used conservation methods are cryopreservation and sterile distilled water, guaranteeing the stability of the characteristics of these fungi, their viability, and their biological potential over time; however, the need to continue evaluating different methods and applications in this type of fungus persists.
\end{abstract}

Keywords: basidiomycetes fungi, fungi strains, culture methods, preservation methods, mushrooms

\section{INTRODUCTION}

Microbial collections are considered centers of biological resources, maintaining strains of different microorganisms in optimal conditions for research, biotechnological, and industrial applications (Hu et al., 2014; Sharma et al., 2017). In order to store under controlled conditions and for a specific time such organisms, it is necessary to apply preservation methods that ensure the viability, availability, and safeguarding of all phenotypic, genotypic, and potentia characteristics industrial of the preserved strains (Henao et al., 2006; Ryan et al. 2004; Morales et al., 2010; Montesinos Matías et al., 2015).

For several years different culture conservation methods have been developed for the maintenance and conservation of microorganisms such as bacteria and fungi, like freeze-drying (lyophilization), cryopreservation, sub-culture (periodic transfer), sterile distilled water, mineral oil layer, drying on filter paper, drying in soil, sand, silica gel, among others (García et al., 2000; Ryan et al., 2004; Weng et al., 2005; Gato, 2010). These methods allow that biological material to be available and stable for varying periods; however, the choice and application of one method or other depends on the type of microorganism to be preserved, the time they wish to keep preserved, the resources, laboratory procedures, and staff in charge (Rico et al., 2004; Smith et al., 2012). In Table 1, the main conservation methods of fungi can be seen along with their advantages and disadvantages.

In general, studies for the maintenance of microbial collections have shown the effects of methods over a given time on the phenotypic, genotypic, feasibility, stability, purity, and reproductive capacity of the strains mainly in filamentous fungi, yeasts, and bacteria of importance for the industry, medicine, agriculture, and the environment. However, the development and research of preservation methods for basidiomycetes have not been studied as extensively as in other types of microorganisms, despite the importance that these fungi have in nature because they are responsible for cycles nutrient replacement, contributing to increased soil fertility; as well as the different secondary metabolites with properties of biotechnology interest and applications in different industry sectors (Cortés et al., 2013; Ladislav Homolka, 2014; Eichlerová et al., 2015). Therefore, this document's objective is to make available to the scientific community a review of the main works carried out on the conservation of basidiomycetes fungi, with an emphasis on edible and medicinal fungi.

$\underline{\text { Table } 1 \text { Advantages and disadvantages of the main fungi culture methods }}$

\begin{tabular}{lc} 
Method & Advantage \\
\hline Decreases the tendency to pleomorphism by \\
some species.
\end{tabular}
some species.

It is simple, safe, and inexpensive, does not require personnel specialized.

Sterile distilled water

It maintains viability, purity, and stability for extended periods.

It also allows to preserve fungi that cannot be preserved by liquid nitrogen or freeze-dried.

Has been successfully used to preserve basidiomycetes.
Reference

Burdsall et al. (1994)

Bueno et al. $(1998)$

The strains can degenerate during storage Martínez et al. (2009) time.

Conservation times are variable and will depend on the fungus to be preserved.

Fernández et al. (2013)

Hu et al. (2014)

Ladislav Homolka (2014)

S.K. Singh (2017) 
There is a low risk of changes in the viability and genotype of the microorganisms.

The method is used for the long-term preservation of fungi.

This method applies to a broad spectrum of fungi. equipment.

Hu et al. (2014)

It requires a bioprotectant to avoid excessive S.K. Singh (2017) dehydration of the cells.

Need a constant supply of liquid nitrogen.

The method can be complicated and requires specialized equipment.

The maintenance of the culture is low cost.

Freeze-drying

The method is applied to a wide range of microorganisms.
It requires a bioprotectant to avoid extracellular and intracellular crystallization.

Limited application in basidiomycetes.
Ladislav Homolka (2014)

Hu et al. (2014)

Fungi can lose its viability.

The storage time is less than a year.

It requires time and labor because it needs subculturing every few months so that it can be expensive.

Useful for small collections of fungus that do not require long-term storage.
There is a risk of contamination with other microorganisms, so it should be continuously checked
Iqbal et al. (2017)

S.K. Singh (2017)

Cui et al. (2018)

Increase the danger of changes in morphology and physiology of the cultured fungus.

In this technique, the fungi continue to grow, and therefore there is a risk of mutation in adverse conditions.

Sterile mineral oi

It is a friendly method for laboratories with limited resources.

It has been used in different fungi, remaining viable for 20 years or more.
It requires periodic verification to assess contamination.
Smith et al. (1983)

Prakash et al. (2013)

Ladislav Homolka (2014)

S.K. Singh (2017)

\section{CULTURE CONSERVATION METHODS}

\section{Sterile distilled water (Castellani method)}

It is a widely used technique for conserving microorganisms such as filamentous fungi, yeasts, and some bacteria due to the high percentages of viability obtained over time (García et al., 2000). As seen in figure 1, the method consists of suspending agar discs or blocks with the colonies of the microorganism in tubes or vials with sterile distilled water, and these are sealed by screw caps, rubber or cotton caps and stored at room temperature (between 20 and $25^{\circ} \mathrm{C}$ ) or in cold storage between 4 and $5{ }^{\circ} \mathrm{C}$ (Castellani, 1963; Nakasone et al., 2004; S.K. Singh, 2017). It is the most preferred method for the maintenance of fungal culture because decreases the tendency to pleomorphism by some species, prevents the attack of mites, is simple, safe, and inexpensive, does not require personnel specialized and maintains viability, purity, and stability for extended periods; also can be applied in fungi that cannot be preserved by liquid nitrogen or freeze-dried (Burdsall et al., 1994; Bueno et al., 1998; Fernández et al., 2013; Martínez et al., 2009).

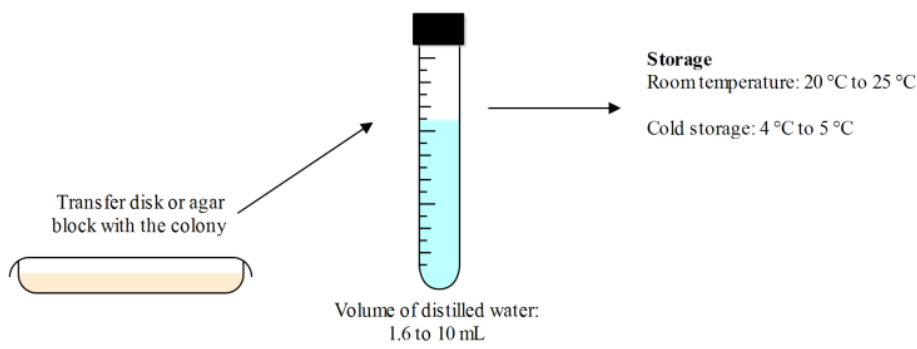

Figure 1 Schematic representation of sterile distilled water culture conservation method

In 1963 Aldo Castellani, in his publication "Further researches on the long viability and growth of many pathogenic fungi and some bacteria in sterile distilled water", showed to the scientific community the progress made by the application of its method, which consisted of preserving strains of filamentous fungi, yeasts, and some bacteria in test tubes with sterile distilled water (8 to 10
$\mathrm{mL}$ ) properly capped, kept at room temperature for different periods (one year or more), and subsequently recovered in test tubes with dextrose agar to assess the efficiency of the method. The results obtained in their studies showed that these strains, after several years, maintained high percentages of viability, average growth, and no changes in their morphology (Castellani, 1963). McGinnis et al (1974) used Castellani's method in their preservation studies, stating that it is a simple, inexpensive, and reliable technique, since its application for the maintenance of 417 isolates of filamentous fungi, yeasts, and aerobic actinomycetes for a period between 12 to 60 months, showed that $93 \%$ (389) of cultures survived in perfect conditions to storage in sterile distilled water Hartung de Capriles et al. (1989) evaluated the preservation of 594 fungal strains for a period of 1 to 20 years by this method, $62 \%$ of the preserved strains (368) were viable and maintained their main morphological characteristics; also $90 \%$ of the strains of different species preserved for 20 years were viable. Bueno et al. (1998) preserved 26 strains of the genera and species: Aspergillus niger, Aspergillus candidus, Fusarium sp, Fusarium moniliforme, Mucor griseocyanum, Syncephalastrum sp., Trichoderma sp., Trichoderma harzianum, and Trichoderma koningii using the method of preservation in sterile distilled water, they demonstrated that the strains of these organisms had a $100 \%$ viability for two years, did not have contamination with bacteria or mites, no changes were observed with the naked eye apparent changes and in macroscopic characteristics in any of the culture studied.

Similar results are evident in other studies, such as the one conducted by Panizo et al. (2005), assessing the feasibility, purity, morphological, macroscopic, and microscopic stability of 411 fungi, preserved in distilled water and sterile minera oil for 3 to 48 years. Statistical analysis showed that of the 170 yeasts evaluated, $100 \%$ were kept viable, pure, and morphologically stable by the two preservation methods of 241 filamentous fungi, $100 \%$ evaluated pure and viable, while $95.4 \%$ were kept pure and viable by both methods used. On the other hand, in the research conducted by Fernández et al. (2013), in which the feasibility, purity, and stability of the main morphological and physiological characteristics of 240 strains of different fungal species belonging to the collection of pathogenic fungal cultures of the Institute of Tropical Medicine "Pedro Kouri" preserved in sterile distilled water for a period of 15 to 20 years, it was obtained that $80 \%$ of the culture was kept in a viable state and without contamination.

For basidiomycetes fungi, the U.S. Department of Agriculture's "Forestry Research Center" conducted a study in which they preserved 151 species of wood degrading fungi for periods of up to 7 years in sterile distillate water; obtaining 
that $94 \%$ of the preserved strains were feasible and growth rates were not affected by the evaluation preservation method; validating that this storage technique has several advantages compared to storing in slanted agar test tubes, such as the long periods during which the isolate can be stored without the need to do periodic transfers, reduced consumption of culture media and increased genetic stability (Burdsall et al., 1994). Similarly, Croan et al. (1999) preserved 35 basidiomycetes fungi that inhabit tropical woods using conservation methods in sterile distilled water, cryopreservation in liquid nitrogen and freeze-dried. As a result, $57 \%$ of the strains stored in sterile distilled water at $4{ }^{\circ} \mathrm{C}$ survived for 2.5 months, while at $15{ }^{\circ} \mathrm{C}, 92 \%$ of the strains survived for ten months, maintaining viability without presenting changes in morphological or biochemical characteristics for both cases. Diogo et al. (2005) came to a similar conclusion when assessing the efficacy for the conservation of 43 species of fungi in sterile distilled water for 12 months; they tested the average growth viability, and sporulation capacity of the strains under study. Richter et al. (2010) managed to conserve stable and viable 14 isolates of basidiomycetes (12 species) fungi for 18 years in tubes with inclined agar and sterile distilled water.

Maia et al. (2012) used as substrate rice and sterile distilled water preservation solution to conservation of the basidiomycetes Agaricus brasiliensis, Pleurotus ostreatus, Pleurotus sajor-caju, and Lentinula edodes. The rice-based substrate in distilled water at room temperature was the most effective method for preserving Agaricus brasiliensis, with a recovery of $100 \%$ of the preserved strains after 12 months; this fungus cannot be stored at low temperatures. Similarly, Karaduman et al. (2012); preserved strains of Schizophyllum commune using 12 different preservation methods for one year, using as response variables the rate of mycelial recovery, mycelial growth, the weight of mycelial biomass, and enzymatic activity of recovered culture. They obtained that mycelium preserved on agar blocks in sterile distilled water at $4{ }^{\circ} \mathrm{C}$ and in glycerol $(15 \%)$ at $20^{\circ} \mathrm{C}$ were the best conservation methods for this type of fungi, and the strains stored on wheat seeds colonized with mycelium in sterile distilled water at $4{ }^{\circ} \mathrm{C}$ and on agar blocks in sterile distilled water at $20{ }^{\circ} \mathrm{C}$, were the alternative methods to preserve Schizophyllum commune.

Palacio et al. (2014) assessed the effect of conservation on sterile distilled water, cryopreservation with glycerol at $10 \%$ temperature of $-20{ }^{\circ} \mathrm{C}$ and $-80{ }^{\circ} \mathrm{C}$, and freeze-dried, of basidiomycete fungi Agaricus blazei, Ganoderma lucidum, Grifola frondosa, and Pleurotus pulmonarius over 12 months. Response variables were feasibility, growth kinetics, biomass production, and polysaccharides. The results obtained after 12 months of conservation, determined that the best method was distilled water at $24{ }^{\circ} \mathrm{C}$, as it achieved the highest percentage of recoverability $(83.3 \%)$, followed by the cryopreservation method at $-80{ }^{\circ} \mathrm{C}$, where $75 \%$ was recovered, without affecting biomass production and polysaccharides; however, for specific cases like Pleurotus pulmonarius suggest cryopreservation at $-80{ }^{\circ} \mathrm{C}$. García-García et al. (2014) evaluated sterile distilled water in the medicinal fungus Humphreya coffeata, using filter paper discs inoculated with the fungus, guaranteeing high viability of the culture for 18 months, without visible morphological changes, contamination by bacteria or other fungi. As observed, sterile distilled water has allowed the conservation of different culture of edible and medicinal fungi between 2.5 months and 48 years, depending on the type of fungus and the conditions of applying the technique.

\section{Cryopreservation}

Cryopreservation is a technique that allows a cell suspension to be stored at a temperature equal to or below the freezing point. Depending on the temperature, this method of preservation can be classified into ordinary freezing $\left(-5\right.$ to $\left.-20^{\circ} \mathrm{C}\right)$ ultra-cold freezing $\left(-50\right.$ to $\left.-80^{\circ} \mathrm{C}\right)$, and freezing with liquid nitrogen $(-150$ to -196 $\left.{ }^{\circ} \mathrm{C}\right)$ (Hernández et al., 2014). It is a long-term preservation method that allows storage microorganisms between one year and twenty years; it also guarantees the viability, purity, and genetic stability of the stored strains. It is one of the most recommended techniques for conserving fungi that cannot be freeze-dried (Nakasone et al., 2004; Ladislav Homolka, 2014). The method consists of previous growth of the culture in Petri dishes with potato dextrose agar or malt extract agar. Portions of the colonized agar are cut and transferred to cryovials with a cryoprotectant; they are brought to containers at low temperature and subsequently stored in cryo-box at $-70{ }^{\circ} \mathrm{C}$ (S.K. Singh, 2017). Several factors affect cryopreservation effectiveness, like microorganisms, cell composition, growth medium, and freezing/storage characteristics (figure 2).

Cryopreservation has some disadvantages such as high cost of the equipment required, energy cost, the need to maintain a constant supply of nitrogen (when applied), the danger that some mechanical and electrical failure will destabilize the temperature as well same specific conditions for the transport of the strains (Arencibia et al., 2008). Also, it is necessary to use a cryoprotective because physicochemical phenomena during freezing can affect cell viability. Major cryoprotectants include glycerol, dimethylsulfoxide, skim milk, inositol, glucose, lactose, and sucrose (Rico et al., 2004). Danell et al. (2002) evaluated five protocols for the preservation of strains of the ectomycorrhizal fungus Cantharellus cibarius in liquid nitrogen using different cryoprotectants, cooling rates, and times of incubation; as a result, they found that the best preservation protocol was the one that used sorbitol and dimethyl sulfoxide at a slow freezing rate of $0.3{ }^{\circ} \mathrm{C} \mathrm{min}^{-1}$, after $72 \mathrm{~h}$ and six days, these remained viable and showed no morphological or physiological changes. Kitamoto et al. (2002); preserved 66 strains of fungi, including Oomycota, Zygomycota, Ascomycota, Basidiomycota, and mycetes by rapid freezing at $-85^{\circ} \mathrm{C}$ with glycerol and ethylene glycol as cryoprotectors at different concentrations; as well as these fungi were preserved using wood sawdust with $65 \%$ moisture. The results obtained in this study showed that with $10 \%$ of glycerol cryoprotectant, strains remain viable and stable for up to 10 years even after defrosting the strains at room temperature and subjecting them to processes of alternating freezing and thawing.

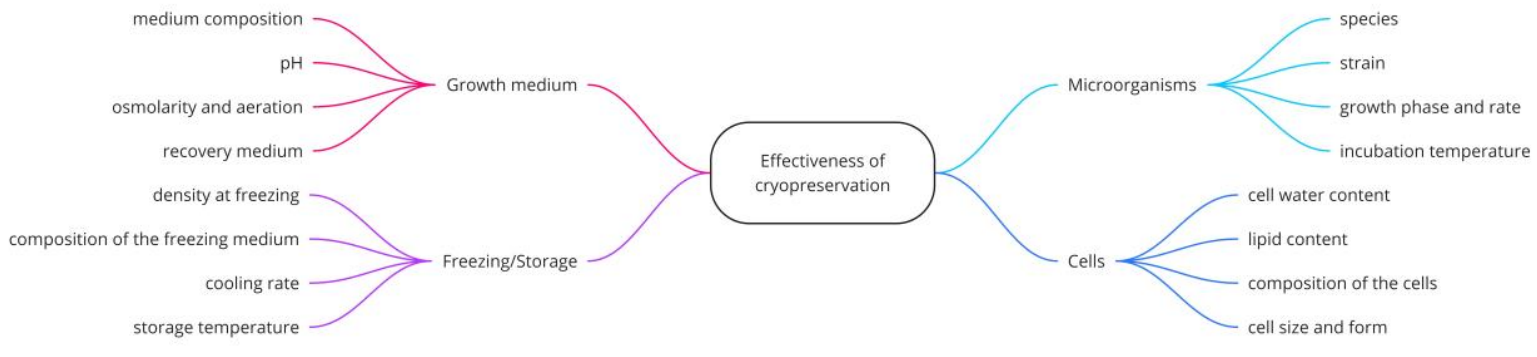

Figure 2 Main factors that affect the effectiveness of cryopreservation. Adapted from Hubálek (2003)

Regarding studies concerning the conservation of edible fungi, the researchers Ohmasa et al. (1996); evaluated the effect of three cryopreservation protocols on the yields of fruiting bodies of the Flammulina velutipes after having preserved two strains (FMC224 and FMC225) at three temperatures $(-20,-85$ and $-196{ }^{\circ} \mathrm{C}$ ), and with three cryoprotectants (glycerol, dimethylsulfoxide, and polyethylene glycol) for seven years. Lara et al. (1998) evaluated the effect of conservation in liquid nitrogen on the production of carpophores of six fungal strains of Pleurotus spp, stored for 15 days at $-196{ }^{\circ} \mathrm{C}$ where the variables of response were: time in days of appearance of the primordia, number mushroom crops obtained, biological efficiency and size of fruiting. As a result, they observed variability in the yields of crops obtained, size of fruiting, and biological efficiency of the strains (55 to $106 \%$ ); however, the cryopreserved strains did not show morphological differences concerning the control.

Mata et al. (2003) used five strains of edible fungi (Lentinula boryana, Lentinula edodes, Pleurotus djamor, Pleurotus pulmonarius, and Volvariella volvacea) inoculated on sorghum seeds to evaluate three protocols for one week; in the first protocol, the sorghum seeds inoculated with the fungi were preserved in cryovials using glycerol and dimethylsulfoxide as cryoprotectants, in the second protocol distilled water was used, and in the third protocol without cryoprotectant. Once the storage time elapsed, the strains were recovered on Petri dishes. The viability, purity, growth rate, and macro and microscopic characteristics of the strains were evaluated, $96.8 \%$ of the strains stored by the three protocols successfully recovered while retaining all their morphological characteristics. However, only strains preserved without cryoprotectant achieved a recovery percentage of 99.2 $\%$, showing that it is suitable for the conservation of basidiomycete fungi and could handle large quantities of commercial fungal strains at reduced production costs. Other research conducted by S. K. Singh, Upadhyay, Kamal, et al. (2004) evaluated the effect of cryopreservation on the survival, yield, and genetic stability of 11 the edible fungi Agaricus bisporus, Agaricus bitorquis, Pleurotus flabellatus, Pleurotus species sajor-caju, Pleurotus ostreatus, Pleurotus sapidus, Auricularia polytricha, Lentinula edodes, Morchella esculenta, and Volvariella volvacea, preserved on wheat grains in cryovials with $15 \%$ glycerol at $-196{ }^{\circ} \mathrm{C}$. The results showed that 9 of the 11 strains conserved did not show significant changes in viability, biological efficiency, the weight of fruiting bodies, and genetic stability.

Ladislav Homolka et al. (2006); developed a new method for the conservation of 442 strains of basidiomycete fungi of different species; by the cryopreservation of the fungal mycelium using agricultural grade perlites as 
support. The cultures were stored in cryotubes $(1.8 \mathrm{~mL})$ for $48 \mathrm{~h}$ up to 3 years in liquid nitrogen; after this time, the ability to maintain laccase production, growth, and the macro and microscopic characteristics of the conserved strains were evaluated. They obtained that $100 \%$ of the strains maintained the viability, purity, morphological characteristics, and laccase production during the evaluated period. In 2007, these same authors evaluated the capacity of 50 strains of basidiomycete fungi preserved by the perlite protocol to survive three successive cycles of freezing and thawing, obtaining that in the first cycle, $100 \%$ of the strains evaluated kept viability, purity, macro, and microscopic characteristics, shape, and speed of growth, as well as the production capacity of laccase, for cycles 2 and $3,96 \%$ of the strains survived while maintaining the same characteristics mentioned above. Therefore, they assured that with this cryopreservation method, the difficulties caused by the interrupted supply of liquid nitrogen or electrical energy during storage could be overcome withou affecting the preserved culture's survival and quality (Ladislav Homolka $\boldsymbol{e t}$ al., 2007)

In a study on the vitality and genetic stability of mycelium in 15 species of white rot fungi, different cryopreservation protocols were evaluated at $-80{ }^{\circ} \mathrm{C}$ and lyophilization. These included variables such as culture medium, cryoprotectants, time, number of infusions, and origin of the samples. The results showed that it is possible to perform adequate conservation of the basidiomycete strains by these techniques; however, in lyophilization, morphological changes occurred in two isolates of Ganoderma adspersum, something that did not occur with freezing (Voyron et al., 2009). The researchers Ladislav Homolka et al. (2010) conserved 30 strains of basidiomycete fungi on pearls in liquid nitrogen for ten years and showed no changes in morphological and genetic characteristics, viability remained stable, as was the enzymatic activity of preserved fungi. On the contrary, in the study conducted by Kaur et al. (2011) on conservation of strains of edible fungi Agaricus bisporus and Pleurotus florida at differen temperatures $\left(25{ }^{\circ} \mathrm{C}\right.$ to $35^{\circ} \mathrm{C}$ and $-20{ }^{\circ} \mathrm{C}$ to $\left.-196{ }^{\circ} \mathrm{C}\right)$ in $10 \%$ glycerol, showed that the viability and recovery of the strains are affected by storage conditions after six months.

In another study conducted by Mantovani D'Agostini et al. (2012), developed alternative techniques in the cryopreservation of basidiomycete fungi, evaluating the effect of different substrates such as whole grains of oats, wheat, rice, and millet and cryoprotective agents such as dimethyl sulfoxide, glycerol, sucrose glucose, polyethylene glycol and malt extract for the conservation of strains of Pleurotus ostreatus by the cryopreservation method at $-20{ }^{\circ} \mathrm{C}$ and $-70{ }^{\circ} \mathrm{C}$ for a period of 1 to 3 years. The results showed that any substrate combined with the cryoprotectants studied effectively preserved mycelium, except for millet grains with polyethylene glycol after three years. Wheat grains combined with any cryoprotectant effectively keep mycelium viable after one year of cryopreservation at $-20^{\circ} \mathrm{C}$, and when combined with sucrose or glucose, they are more effective after three years. Eichlerová et al. (2015) used two protocols: pearls and plastic straws for the cryopreservation of Pleurotus ostreatus and Trametes versicolor; these strains were frozen at $-70{ }^{\circ} \mathrm{C}$ at a speed of $1{ }^{\circ} \mathrm{C} \mathrm{min} \mathrm{min}^{-1}$ using $5 \%$ glycerol as a cryoprotectant and then stored in liquid nitrogen for 12 years, in order to assess the viability, growth rate, morphological characteristics, laccase enzyme activity, and decolorization test. As a result of this investigation, they obtained that $100 \%$ of the strains conserved by these methods managed to remain viable, retained their macro and microscopic characteristics, and maintained their enzymatic activity.

\section{Freeze-drying or lyophilization}

It is a long-term conservation method that guarantees the genetic stability and viability of the organisms preserved for periods of 10 or more years, also prevents the occurrence of successive generations (Arencibia et al., 2008). The method stops the microorganism's metabolism and extracts water from the frozen cells by sublimation of the ice under high vacuum conditions (Morales $\boldsymbol{e t}$ al. 2010). The culture of the microorganism is carried out in Petri dishes with potato dextrose agar or malt extract agar, then spore or hyphae suspensions are transferred in glass ampoules, these are frozen at $-70{ }^{\circ} \mathrm{C}$ for 4 to $6 \mathrm{~h}$, then lyophilized and later stored in cold storage or room temperature (S.K. Singh, 2017). The dehydration of the cells, necessary to avoid intracellular crystallization during freezing, is regulated through the cooling rate and depends on the cell's size and the thickness of the cell wall (Ladislav Homolka, 2014). The addition of a cryoprotective agent is required to prevent the cells from suffering some damage, such as monosodium glutamate, glucose, sucrose trehalose, skim milk, inositol; other cryoprotectants such as glycerol, dimethylsulfoxide, 1,2 propane-diol, ethylene glycol, ethanol, methanol, polyethylene glycol are used; however most of these are toxic (Arencibia et al., 2008; Gato, 2010; Ladislav Homolka 2014). This method is highly recommended for its convenience for storage and transport of the strains, as they can be stored at room temperature (Pinzón Gutiérrez et al., 2009); however, it is a high-cost technique due to infrastructure and equipment requirements; thus, it cannot be applied in laboratories with limited resources (Gato, 2010; Montesinos Matías et al., 2015).
In some cases, the lyophilization of basidiomycetes has been successful, which has increased interest in this method. Tan et al. (1991) evaluated the method in 4 ascomycete strains (Alternaria bataticola, A. dianthicola, Cercospora autensis, and Chaetomium balloonsum) and two strains of basidiomycetes (Coprinopsis $\mathrm{sp}$ and Schizophyllum commune); finding that all strains were recovered after the lyophilization process with differences in the survival rate which was lower in basidiomycetes compared to the ascomycetes evaluated; the rate increased in both phylum when incubated in media containing trehalose.

Croan et al. (1999); applied this method of preservation in Pleurotus ostreatus, $P$. populinus, and $P$. pulmonarius, which showed an intense colonization mycelial growth and more efficient substrate after preservation compared to non-lyophilized, at cold storage $\left(4^{\circ} \mathrm{C}\right), 57 \%$ of the isolates survived for 2.5 months at $15{ }^{\circ} \mathrm{C}$, and $92 \%$ of the isolates survived ten months. S. K. Singh, Upadhyay, Yadav, et al. (2004) worked on this method with 11 strains finding a recovery percentage of at least $90 \%$ after three months of storage. In a work development on the vitality and genetic fidelity with mycelium of fungi of the white-rot. Voyron et al. (2009) evaluated 12 lyophilization protocols with 15 strains of basidiomycetes; they found that all the isolates maintain the vitality in two of the 12 evaluated protocols, the morphological characteristics are maintained in 13 of the 15 strains, and the physiological characteristics were not modified after one month of storage. Palacio et al. (2014) evaluated the viability of 4 strains through 3 conservation methods, finding that under the conditions they applied, lyophilization was inappropriate for the isolates since none was viable after 1,6 , and 12 months of conservation. Recently in a study conducted by Sun et al. (2018), evaluated the effect of the conservation method on the Cordyceps militaris; the results showed that the growth rate of the fungus was not affected by age and sub-culture, maintaining vitality for 12 months.

\section{Sub-culture}

It is considered a short-term conservation technique since microbial cultures must be reactivated and renewed periodically to maintain the characteristics that make them important; therefore, these time intervals depend on the type of microorganism to be preserved. Some microorganisms need to be transferred to new culture media after days, weeks, or months (usually in less than a year), while other culture preservation methods managed to conserve for months or years; however, it is one of the most commonly used techniques for basidiomycete fungi since they cannot be easily preserved by other methods (Nakasone et al., 2004; Ladislav Homolka, 2014).

This method consists of periodically transferring the strains of the microorganism of interest to Petri dishes or test tubes with fresh culture media (potato dextrose agar, malt extract agar, nutritive agar, Sabouraud agar, YGC agar), with adequate conditions of incubation and storage temperature for the optimal development of the microorganism, this process is repeated in time intervals that guarantee a new fresh culture before the loss of the predecessor culture (Pinzón Gutiérrez et al. 2009). Once the strains are ready, they are kept refrigerated at $4{ }^{\circ} \mathrm{C}$, where they can remain for a while and use them whenever required (Bazán et al., 2004); however, continually requires verification for viability, contamination, and growth characteristics of the culture (S.K. Singh, 2017).

It is a method that has several drawbacks, including the selection of phenotypic variants (pleomorphic growth) and mutant gene, the loss of pathogenicity, virulence, or sporulation. It is a universally applicable technique currently used in most low-budget collections or as a second maintenance method. Generally, the storage temperature in this method is ambient; and one way to avoid performing several cultures is cold storage or using wet perlite; which can be an alternative method that has shown excellent results in maintaining strains for up to four years (Nakasone et al., 2004; L. Homolka et al., 2008; Ladislav Homolka, 2014)

Regarding edible fungi, Bermeo Escobar et al. (2020) analyzed the influence of conservation in sterile distilled water, sterile mineral oil, sterile saline, and periodic subculture on the purity and viability of the Pleurotus ostreatus strains, finding that the conservation methods evaluated maintained the characteristics of the microorganism after four months at $4{ }^{\circ} \mathrm{C}$. Yin et al. (2017) identified that the use of subculture of Cordyceps militaris stored for ten days at $23{ }^{\circ} \mathrm{C}$ could impact gene strain degeneration, restricting the large-scale production of this medicinal and edible mushroom.

\section{Sterile mineral oil}

It is an alternative method commonly used to conserve mycelium or fungi that are not sporulated or have poor sporulation, which is susceptible to lyophilization and freezing; also, when deep freezing is not an option, due to its high cost. With this technique, the culture can maintain its viability for several years or even up to 32 years at room temperature or temperatures between $15{ }^{\circ} \mathrm{C}$ and 20 ${ }^{\circ} \mathrm{C}$ (Nakasone et al., 2004; Ladislav Homolka, 2014)

It is a method of suppressing evaporation. It consists of completely covering the culture in a tube (after its development in a solid medium), with a layer of sterile mineral oil or sterile petroleum jelly $(1 \mathrm{~cm})$, tubes are stored in a vertical position at cold storage or room temperature, preventing the evaporation of the water contained in the culture medium and avoiding the increase of osmotic pressure 
(S.K. Singh, 2017). It is a simple, economical, and fast method, which does not require expensive equipment, maintains the viability of most species, and reduces mite contamination; likewise, strains can be kept at room temperature or refrigerated between 1 to 47 years (Rico et al., 2004; Panizo et al., 2005). Some disadvantages of the method are the appearance of contamination with other fungi, delayed growth of recovered strains, and that the fungus can continue its growth generating possible mutants (Montesinos Matías et al., 2015).

Buell et al. (1947) evaluated 1800 cultures of the Tropical Fungus Culture Collection by determining that this method had an additional meaning by emphasizing, at that time, the lack of knowledge of some of the fundamenta problems involved and an additional application in the sense that it looked promising as a useful tool with highly practical advantages. Stebbins et al. (1949) evaluated 626 basidiomycetes, of which the majority were viable, excep Peniophora sambuci (currently Xylodon sambuci), and two isolates of Sebacina cinerea (currently Basidiodendron cinereum). They presented a more vigorous growth compared to those that were not preserved in oil. Smith et al. (1983) evaluated the viability of 58 fungi, belonging to the Commonwealth Mycological Institute, preserved by this method since 1950, finding that 47 of the isolates were viable after 32 years of storage and 7 of those that did not survive the tota period, remained viable for 20 years or more, confirming that the method is a useful alternative to storage in liquid nitrogen and for mycelial forms that do not survive lyophilization. Johnson et al. (1992) assessed the survival of 393 species of wood-living fungi stored for 1.5 years, recovering $98 \%$ of the strains preserved in oil compared to a $26 \%$ recovery of those preserved in water, concluding that this method is adequate for the preservation of basidiomycetes fungi. López Lastra et al. (2002) compared five conservation methodologies with nine strains of entomopathogenic fungi, finding that simple method such as the use of water or oil is very suitable for maintaining essentia characteristics such as viability and infectivity. L. Homolka et al. (2008) evaluated the survival of 35 basidiomycete strains stored in oil at $4{ }^{\circ} \mathrm{C}$ for four years, finding $47.3 \%$ recovery of the cultures evaluated.

\section{Recent methods and future trends}

Edible and medicinal mushrooms represent an alternative to obtain nutrients or active compounds in the diet, being a possible strategy for reducing food insecurity (Cuesta et $\boldsymbol{a l} .$, 2017), evaluating their impact on health and nutrition, promoting industrial production, and the application and research of culture conservation methods. In addition to the previously mentioned methods, it is essential to evaluate other preservation techniques that have been applied mainly to entomopathogenic and phytopathogenic fungi, showing promising results in viability and storage time, which could be evaluated in edible and medicinal mushrooms. Among these techniques are the gelatin method (Igor Forigo et al. 2017), sterile cotton balls moistened with growth medium (Al-Bedak et al. 2019), the rye seed method (Cui $\boldsymbol{e t}$ al., 2018), silica gel (Ayala-Zermeño et al., 2017), cellophane pieces (Hu et al., 2014) and sodium alginate encapsulation (Mancera-López et al., 2019; Bhai, 2020). It is also essential to continue studying traditional methods and their application in edible and medicinal fungi, continuing with the standardization of parameters, adaptation, and fungal species evaluation.

\section{CONCLUSION}

Edible and medicinal mushrooms have various industrial applications, this requires adequate knowledge of different conservation methodologies that allow preserving all their genetic potential and avoid the deterioration of essential strains, as well as knowing what method is applied for each fungus depending on their particular characteristics. The methods that have shown the best results for the conservation of edible and medicinal fungi are sterile distilled water (Castellani method) and cryopreservation; however, the choice will depend on the type of microorganism and the economic capacity and infrastructure of the laboratory.

Freeze-drying is a simple, fast method that allows long-term preservation; however, equipment, infrastructure, and maintenance costs must be considered, and some mycelial forms do not survive, which requires prior studies to be implemented. Subculture is a short-term method suitable for low-budget laboratories or as the first conservation method in a new laboratory, but the changes that the microorganism may have during storage and the time of dedication for the maintenance of the strains should be considered. Finally, the conservation of edible and medicinal mushrooms in sterile mineral oil requires further study to be recommended for the preservation of this type of microorganisms.

\section{REFERENCES}

Al-Bedak, O. A., Sayed, R. M., \& Hassan, S. H. A. (2019). A new low-cost method for long-term preservation of filamentous fungi. Biocatalysis and Agricultural Biotechnology, 22, $101417 . \quad$ doi https://doi.org/10.1016/j.bcab.2019.101417
Arencibia, D., Rosario, L., \& Gámez, R. (2008). Métodos generales de conservación de microorganismos. La Habana: Finlay.

Ayala-Zermeño, M. A., Gallou, A., Berlanga-Padilla, A. M., Andrade-Michel, G. Y., Rodríguez-Rodríguez, J. C., Arredondo-Bernal, H. C., \& Montesinos-Matías, R. (2017). Viability, purity, and genetic stability of entomopathogenic fungi species using different preservation methods. Fungal Biology, 121(11), 920-928. doi: 10.1016/j.funbio.2017.07.007

Bazán, D., Salas, N., Aguirre, R., Bravo, M., Becerra, E., Lengua, R., Bautista, M. (2004). Análisis comparativo del cultivo de cepas de Pleurotus ostreatus y Pleurotus eringii. Revista Peruana de Ingeniería Química, 7(1), 24 29.

Bermeo Escobar, L. P., Penagos González, J. P., Orjuela Rodríguez, M., \& Castro-Ríos, K. (2020). Effect of culture preservation methods in th stability and nutritional characteristics of Pleurotus ostreatus. Asian Journal of Microbiology, Biotechnology \& Environmental Sciences, 22(2), 359-368.

Bhai, R. (2020). Preservation and long-term storage of Trichoderma spp. by sodium alginate encapsulation. Journal of Plantation Crops, 48(1), 36-44. doi: 10.25081/jpc.2020.v48.i1.6215

Buell, C. B., \& Weston, W. H. (1947). Application of the mineral oil conservation method to maintaining collections of fungous cultures. American Journal of Botany, 34(10), 555-561. doi: 10.1002/j.1537-2197.1947.tb13030.x

Bueno, L., \& Gallardo, R. (1998). Preservación de hongos filamentosos en agua destilada estéril. Revista Iberoamericana de Micologia, 15, 166-168.

Burdsall, H., \& Dorworth, E. (1994). Preserving cultures of wood-decaying basidiomycotina using sterile distilled water in cryovials. Mycological Society of America, 86(2), 257-280. doi: 10.2307\%2F3760650

Castellani, A. (1963). Further researches on the long viability and growth of many pathogenic fungi and some bacteria in sterile distilled water Mycopathologia et Mycologia Applicata, 20(1-2), 1-6. doi: 10.1007/BF02054872 Cortés, A., \& Mosqueda, T. (2013). Una mirada a los organismos fúngicos Fábricas versátiles de diversos metabolitos secundarios de interés biotecnológico. Revista Química Viva, 12(2), 64-90.

Croan, S. C., Burdsall, H. H., \& Rentmeester, R. M. (1999). Preservation of tropical wood-inhabiting basidiomycetes. Mycologia, 91(5), 908-908. doi $10.2307 / 3761546$

Cuesta, M.-C., \& Castro-Ríos, K. (2017). Mushrooms as a strategy to reduce food insecurity in Colombia. Nutrition \& Food Science, 47(6), 817-828. doi: 10.1108/nfs-03-2017-0039

Cui, H., Ren, X., Yun, L., Hou, Q., Feng, F., \& Liu, H. (2018). Simple and inexpensive long-term preservation methods for Phytophthora infestans. Journal of Microbiological Methods, 152, 80-85. doi: 10.1016/j.mimet.2018.07.020

Danell, E., \& Flygh, G. (2002). Cryopreservation of the ectomycorrhizal mushroom Cantharellus cibarius. Mycological Research, 106(11), 1340-1342. doi: $\underline{10.1017 / \mathrm{S} 0953756202006706}$

Diogo, H. C., Sarpieri, A., \& Pires, M. C. (2005). Preservação de fungos em água destilada. Anais Brasileiros de Dermatologia, 80(6), 591-594. doi: 10.1590/s0365-05962005000700004

Eichlerová, I., Homolka, L., Tomšovský, M., \& Lisá, L. (2015). Long term storage of Pleurotus ostreatus and Trametes versicolor isolates using differen cryopreservation techniques and its impact on laccase activity. Fungal Biology, 119(12), 1345-1353. doi: 10.1016/j.funbio.2015.10.004

Fernández, C., Díaz, L., Illnait, M., Aragonés, C., Martínez, G., Perurena, M., \& Rodríguez, I. (2013). Conservación de cultivos de hongos de importancia médica en agua destilada. Revista Cubana de Medicina Tropical, 65(3), 361-369.

García-García, M., Rocha-Zavaleta, L., Valdez-Cruz, N. A., \& Trujillo-Roldán, M. A. (2014). Conservation of the mycelia of the medicinal mushroom Humphreya coffeata (Berk.) Stey. in sterile distilled water. MethodsX, 1(1), 1922. doi: $10.1016 /$ j.mex.2014.04.002

García, M., \& Uruburu, F. (2000). La conservación de cepas microbianas Actualidad SEM, 30, 12-16.

Gato, Y. (2010). Métodos de conservación y formulación de Trichoderma harzianum rifai. Revista Fitosanidad, 14(3), 189-195.

Hartung de Capriles, C., Mata, S., \& Middelveen, M. (1989). Preservation of fungi in water (Castellani): 20 years. Mycopathologia, 106(2), 73-79. doi: 10.1007/BF00437084

Henao, I., Franco, M., \& Marín, G. (2006). Evaluación de métodos de conservación para Aspergillus niger con actividad enzimática amilolítica. Universitas scientiarum, Revista de la Facultad de Ciencias, 11(2), 51-60.

Hernández, D., \& Loaiza, A. (2014). Selección de un método para la conservación y preservación de Actinomicetos aislados del suelo del Jardín Botánico de la Universidad Tecnológica de Pereira. Universidad Tecnológica de Pereira, Pereira.

Homolka, L. (2014). Preservation of live cultures of basidiomycetes - Recent methods. Fungal Biology, 118(2), 107-125. doi: 10.1016/j.funbio.2013.12.002

Homolka, L., \& Lisá, L. (2008). Long-term maintenance of fungal cultures on perlite in cryovials - an alternative for agar slants. Folia Microbiol (Praha), 53(6), 534-536. doi: 10.1007/s12223-008-0084-0

Homolka, L., Lisá, L., Eichlerová, I., Valášková, V., \& Baldrian, P. (2010). Effect of long-term preservation of basidiomycetes on perlite in liquid nitrogen 
on their growth, morphological, enzymatic and genetic characteristics. Fungal Biology, 114(11-12), 929-935. doi: 10.1016/i.funbio.2010.08.009

Homolka, L., Lisá, L., \& Nerud, F. (2006). Basidiomycete cryopreservation on perlite: evaluation of a new method. Cryobiology, 52(3), 446-453. doi 10.1016/j.cryobiol.2006.02.003

Homolka, L., Lisá, L., \& Nerud, F. (2007). Basidiomycete cultures on perlite survive successfully repeated freezing and thawing in cryovials withou subculturing. Journal of Microbiological Methods, 69(3), 529-532. doi: 10.1016/j.mimet.2006.09.004

Hu, X., Webster, G., Xie, L., Yu, C., Li, Y., \& Liao, X. (2014). A new method for the preservation of axenic fungal cultures. Journal of Microbiological Methods, 99(1), 81-83. doi: 10.1016/j.mimet.2014.02.009

Hubálek, Z. (2003). Protectants used in the cryopreservation of microorganisms. Cryobiology, 46(3), 205-229. doi: 10.1016/S0011-2240(03)00046-4

Igor Forigo, B., Breno Cezar Marinho, J., \& Fernando Cezar, J. (2017) Evaluation of the gelatin technique for the preservation of phytopathogenic fungi. Bioscience Journal, 33(4), 923-932. doi: 10.14393/BJ-v33n4a2017-37116

Iqbal, S., Ashfaq, M., Humayun Malik, A., Inam-ulhaq, Saifullah Khan, K., \& Mathews, P. (2017). Isolation, preservation and revival of Trichoderma viride in culture media. Journal of Entomology and Zoology Studies, 5(3), 1640-1646.

Johnson, G. C., \& Martin, A. K. (1992). Survival of Wood-Inhabiting Fung Stored for 10 Years in Water and under Oil. Canadian Journal of Microbiology, 38(8), 861-864. doi: 10.1139/m92-140

Karaduman, A. B., Atli, B., \& Yamaç, M. (2012). An example for comparison of storage methods of macrofungus cultures: Schizophyllum commune. Turkish Journal of Biology, 36, 205-212. doi: 10.3906/bot-1102-8

Kaur, L., Dhanda, S., Sodhi, H. S., Kapoor, S., \& Khanna, P. K. (2011). Storage and preservation of temperate mushroom cultures, Agaricus bisporus and Pleurotus florida. Indian Journal of Microbiology, 51(2), 234-238. doi 10.1007/s12088-011-0152-Z

Kitamoto, Y., Suzuki, A., Shimada, S., \& Yamanaka, K. (2002). A new method for the preservation of fungus stock cultures by deep-freezing. Mycoscience, 43(2), 143-149. doi: 10.1007/s102670200021

Lara, I., Mata, G., \& Gaitán, R. (1998). Evaluación del efecto de la criopreservación de cepas de Pleurotus spp . sobre la producción de carpóforos. Revista Iberoamericana de Micologia, 15(1), 44-47.

López Lastra, C. C., Hajek, A. E., \& Humber, R. A. (2002). Comparing methods of preservation for cultures of entomopathogenic fungi. Canadian Journal of Botany, 80(10), 1126-1130. doi: 10.1139/b02-090

Maia, S. C., Toledo, R. C. C., Almeida, A. P. M. M., da Silva, R., Rinker, D. L. \& Dias, E. S. (2012). Low-cost and low maintenance preservation of Agaricus brasiliensis cultures. World Journal of Microbiology and Biotechnology, 28(6), 2411-2416. doi: 10.1007/s11274-012-1050-1

Mancera-López, M. E., Izquierdo-Estévez, W. F., Escalante-Sánchez, A., Ibarra J. E., \& Barrera-Cortés, J. (2019). Encapsulation of Trichoderma harzianum conidia as a method of conidia preservation at room temperature and propagation in submerged culture. Biocontrol Science and Technology, 29(2), 107-130. doi 10.1080/09583157.2018.1535053

Mantovani D'Agostini, T. R., Tanaka, H. S., Umeo, S. H., Zaghi Junior, L. L., do Valle, J. S., Paccola-Meirelles, L. D., . . . Colauto, N. B. (2012). Cryopreservation at -20 and $-70{ }^{\circ} \mathrm{C}$ of Pleurotus ostreatus on gains. Indian Journal of Microbiology, 52(3), 484-488. doi: 10.1007/s12088-012-0289-4

Martínez, A., León, M., \& González, G. (2009). Conservación de cepas de Candida utilis en agua destilada estéril. ICIDCA, XLIII(2), 47-50.

Mata, G., \& Pérez-Merlo, R. (2003). Spawn viability in edible mushrooms after freezing in liquid nitrogen without a cryoprotectant. Cryobiology, 47(1), 14-20. doi: 10.1016/S0011-2240(03)00064-6

McGinnis, M., Padhye, A., \& Ajello, L. (1974). Storage of stock cultures of filamentous fungi, yeasts, and some aerobic actinomycetes in sterile distilled water. Applied Microbiology, 28(2), 218-222. doi: 10.1128\%2Faem.28.2.218$\underline{222.1974}$

Montesinos Matías, R., Ayala Zermeño, M. A., \& Berlanga Padilla, A. M. (2015). Manual para la conservación y mantenimiento de hongos entomopatógenos (1ra ed.). Mexico: SENASICA.

Morales, Y., Duque, E., Rodríguez, O., De la Torre, J., Martínez, R., Pérez, R., \& Muñoz, J. (2010). Bacterias preservadas, una fuente importante de recursos biotecnológicos. BioTecnología, 14(2), 11-29.

Nakasone, K., Peterson, S., \& Jong, S.-C. (2004). Preservation and distribution of fungal cultures Biodiversity of fungi: inventory and monitoring methods (pp. 37 47). Amsterdam: Elsevier Academic Press.

Ohmasa, M., Tsunoda, M., Babasaki, K., Hiraide, M., \& Harigae, H. (1996). Fruit-body production of test cultures of Flammulina velutipes preserved for seven years by freezing at three different temperatures. Mycoscience, 37(4), 449454. doi: $10.1007 / \mathrm{bf} 02461002$

Palacio, A., Gutiérrez, Y., Rojas, D., Atehortúa, L., \& Zapata, P. (2014). Viability of Basidiomycete fungal strains under different conservation methods cryopreservation vs. freeze-drying processes. Actualidades Biológicas, 36(100), $13-21$.
Panizo, M., Reviákina, V., Montes, W., \& González, G. (2005). Mantenimiento y preservación de hongos en agua destilada y aceite mineral. Revista de la Sociedad Venezolana de Microbiología, 25(1), 35-40.

Pinzón Gutiérrez, Y. A., Bustamante, S. L., \& Buitrago, G. (2009). Evaluación de métodos para la conservación de hongos fitopatógenos del ñame (Dioscorea $\mathrm{sp}$ ). Revista Colombiana de Biotecnología, 11(2), 8-18

Prakash, O., Nimonkar, Y., \& Shouche, Y. S. (2013). Practice and prospects of microbial preservation. FEMS Microbiology Letters, 339(1), 1-9. doi: 10.1111/1574-6968.12034

Rico, M., Piattoni, C., Gonzalez, C., Monela, R., Latorre, M., \& Lurá, M. (2004). Viabilidad de cepas fúngicas conservadas mediente diferentes métodos FABICIB, 8, 163-172. doi: 10.14409/fabicib.v8i1.744

Richter, D. L., Kangas, L. C., Smith, J. K., \& Laks, P. E. (2010). Comparison of effectiveness of wood decay fungi maintained by annual subculture on agar and stored in sterile water for 18 years. Canadian Journal of Microbiology, 56(3), 268-271. doi: 10.1139/W10-001

Ryan, M. J., \& Smith, D. (2004). Fungal genetic resource centres and the genomic challenge. Mycological Research, 108(12), 1351-1362. doi: 10.1017/S0953756204001650

Sharma, S. K., Kumar, R., Vaishnav, A., Sharma, P. K., Singh, U. B., \& Sharma, A. K. (2017). Microbial Cultures: Maintenance, Preservation and Registration Modern Tools and Techniques to Understand Microbes. Heidelberg: Springer International Publishing.

Singh, S. K. (2017). Ex situ Conservation of Fungi: A Review Developments in Fungal Biology and Applied Mycology (pp. 20). Singapore: Springer Nature Singapore.

Singh, S. K., Upadhyay, R. C., Kamal, S., \& Tiwari, M. (2004). Mushroom cryopreservation and its effect on survival, yield and genetic stability. Cryo Letters, 25(1), 23-32.

Singh, S. K., Upadhyay, R. C., Yadav, M. C., \& Tiwari, M. (2004). Development of a novel lyophilization protocol for preservation of mushroom mycelial cultures. Current Science, 87(5), 568-570.

Smith, D., \& Onions, A. H. S. (1983). A comparison of some preservation techniques for fungi. Transactions of the British Mycological Society, 81(3), 535 540. doi: 10.1016/s0007-1536(83)80122-3

Smith, D., \& Ryan, M. (2012). Implementing best practices and validation of cryopreservation techniques for microorganisms. Scientific World Journal, 2012, 805659. doi: 10.1100/2012/805659

Stebbins, M. E., \& Robbins, W. J. (1949). Mineral Oil and Preservation of Fungous Cultures. Mycologia, 41(6), 632-636. doi $\underline{10.1080 / 00275514.1949 .12017806}$

Sun, H., Hu, T., Guo, Y., \& Liang, Y. (2018). Preservation affects the vegetative growth and fruiting body production of Cordyceps militaris. World Journal of Microbiology and Biotechnology, 34(11), 166. doi: 10.1007/s11274-018-2550-4

Tan, C. S., Stalpers, J. A., \& van Ingen, C. W. (1991). Freeze-drying of fungal hyphae. Mycologia, 83(5), 654-657. doi: 10.1080/00275514.1991.12026065

Voyron, S., Roussel, S., Munaut, F., Varese, G. C., Ginepro, M., Declerck, S., \& Filipello Marchisio, V. (2009). Vitality and genetic fidelity of white-rot fung mycelia following different methods of preservation. Mycological Research 113(10), 1027-1038. doi: 10.1016/j.mycres.2009.06.006

Weng, Z., Olvido, E., \& Álvarez, I. (2005). Consevación de microorganismos: ¿Qué debemos conocer? Revista Cubana de Higiene y Epidemiología, 43(3), 1-4. Yin, J., Xin, X., Weng, Y., \& Gui, Z. (2017). Transcriptome-wide analysis reveals the progress of Cordyceps militaris subculture degeneration. PLoS One, 12(10), e0186279. doi: 10.1371/journal.pone.0186279 